\title{
Fear of becoming pregnant among female healthcare students in Spain
}

Felipe Navarro-Cremades, Antonio Palazon-Bru, Maria A Arroyo-Sebastian, Luis Gomez Perez, Armina Sepehri, Salvador MartinezPerez, Dolores Marhuenda-Amoros, Maria M Rizo-Baeza, Vicente F Gil-Guillen

The inconsistent use of hormonal contraceptive methods can result, during the first year of use, in one in twelve women still having an undesired pregnancy. This may lead to women experiencing fear of becoming pregnant (FBP). We have only found one study examining the proportion of FBP among women who used hormonal contraceptives. To gather further scientific evidence we undertook an observational, cross-sectional study involving 472 women at a Spanish university in 2005-2009. The inclusion criteria were having had vaginal intercourse with a man in the previous three months and usual use for contraception of a male condom or hormonal contraceptives, or no method of contraception. The outcome was FBP. The secondary variables were contraceptive method used (oral contraceptives; condom; none), desire to increase the frequency of sexual relations, frequency of sexual intercourse with the partner, the sexual partner not always able to ejaculate, desire to increase the partner's time before orgasm, age and being in a stable relationship. A multivariate logistic regression model was used to determine the associated factors. Of the 472 women, 171 experienced FBP (36.2\%). Factors significantly associated $(p<0.05)$ with this FBP were method of contraception (condom and none), desire to increase the partner's ability to delay orgasm and higher frequency of sexual intercourse with the partner. There was a high proportion of FBP, depending on the use of efficient contraceptive methods. A possible solution to this problem may reside in educational programmes. Qualitative studies would be useful to design these programmes. 
1 Authors: Felipe Navarro-Cremades, $\mathrm{MD}, \mathrm{PhD}^{1}$, Antonio Palazón-Bru, $\mathrm{PhD}^{1}$, María del Ángel

2 Arroyo-Sebastián, $\mathrm{MD}^{2}$, Luis Gómez-Pérez, $\mathrm{MD}, \mathrm{PhD}^{3}$, Armina Sepehri, $\mathrm{PhD}^{1}$, Salvador

3 Martínez-Pérez, $\mathrm{MD}, \mathrm{PhD}^{4}$, Dolores Marhuenda-Amorós, $\mathrm{MD}, \mathrm{PhD}^{3}$, María Mercedes Rizo-

4 Baeza, $\mathrm{PhD}^{5}$, Vicente Francisco Gil-Guillén, $\mathrm{MD}, \mathrm{PhD}^{1}$.

5

6 1: Department of Clinical Medicine, Miguel Hernández University, San Juan de Alicante,

7 Alicante, Spain.

8 2: Health Centre of San Juan de Alicante, Conselleria de Sanitat, San Juan de Alicante, Alicante, 9 Spain.

10 3: Department of Pathology and Surgery, Miguel Hernández University, San Juan de Alicante, 11 Alicante, Spain.

12 4: Department of Histology and Anatomy, Miguel Hernández University, San Juan de Alicante, 13 Alicante, Spain.

14 5: Department of Nursing, University of Alicante, San Vicente del Raspeig, Alicante, Spain. 15

16 Corresponding author: Prof. A. Palazón-Bru, PhD. Department of Clinical Medicine, Miguel

17 Hernández University, Carretera de Valencia - Alicante S/N 03550 San Juan de Alicante.

18 Telephone: +34 965919449. Fax: +34 965919450. E-mail: antonio.pb23@gmail.com 


\section{INTRODUCTION}

23 The last 35 years have seen significant advances in the development of contraceptive methods

24 (World Health Organization, 2010). This has resulted in these methods being highly effective if

25 used correctly, particularly the hormonal contraceptives (World Health Organization, 2011;

26 World Health Organization, 2010). Nevertheless, a certain percentage of women use hormonal

27 contraceptive methods inconsistently, either due to side effects or to lack of compliance taking

28 them (Rosenberg, Waugh \& Meehan, 1995; Lete et al., 2008). During the first year of use of

29 these methods approximately one in every 12 women may have an unwanted pregnancy (Trusell

$30 \&$ Kost, 1987). For these reasons women, even if they use hormonal contraceptive methods, may

31 experience fear of having an unwanted pregnancy. This is translated into relief when they start

32 their monthly menstruation after having had vaginal intercourse with a man who ejaculated (Lete

33 et al., 2008).

34 Considering the lack of papers examining this fear, we undertook a study in a population

35 of university students studying the healthcare sciences, assessing which women experienced fear

36 of becoming pregnant (FBP). Unlike other studies (Lete et al., 2008), our study also included

37 women who commonly relied on a male condom for hormonal contraception and women who

38 did not use any contraceptive method at all. We also determined the factors related with their

39 sexual behaviour that could be associated with this FBP. The results suggest the need for more

40 education about preventing an undesired pregnancy in future healthcare workers.

41

42 MATERIALS \& METHODS

43 Study population 
44 The study population comprised female students of the faculties teaching healthcare sciences

45 (Medicine, Physiotherapy, Pharmacy, Podiatry and Occupational Therapy) at Miguel Hernandez

46 University in San Juan de Alicante (Alicante, Spain). The majority of students in these faculties

47 are single women, with the following characteristics: interested in studying healthcare sciences,

48 age 18-25 years, and a middle to high socio-economic status.

49 In Spain, a female college student becoming pregnant without wanting to can be

50 associated with a social stigma. This cultural attitude has existed for many years and still endures

51 in our country, despite the modernization of standards and changes in habits in these situations.

52 FBP may also be related with the situation as perceived by the woman.

53 Study design and participants

54 This cross-sectional observational study, undertaken between February 2005 and February 2009,

55 selected a sample of university students studying healthcare sciences at Miguel Hernández

56 University. The sample comprised all second-year female students studying Occupational

57 Therapy and third-year female students studying Medicine who attended lectures on a particular

58 day during the study period (decided by the research team) and who were willing to participate in

59 the study and complete the questionnaire voluntarily (Table S1). This questionnaire was

60 completed in the lecture halls generally used by the students for their respective degree courses.

61 The inclusion criteria required that the women had to have had vaginal intercourse with a man

62 during the previous three months and have generally used either the male condom or hormonal

63 methods for contraception or not used any contraceptive method at all. This information was

64 assessed by specific questions on the above-mentioned questionnaire (Table S1: General items

65 and Changes in sex life items).

66 Variables and measurements 
67 The information was collected with an original questionnaire (Table S1) that was designed by an 68 expert committee, based on their professional experience and relevant scientific articles. Prior to 69 completing the questionnaire it was explained to the students, who were asked to be sincere in 70 their answers. The co-ordination and explanation of the questionnaire were always done by the 71 same researcher, who also resolved any doubts during the process of completion of the 72 questionnaire, which took about 25 minutes to complete. Previously, a pilot study had been 73 undertaken to assess its comprehension, obtain preliminary data and determine whether the 74 psychometric properties of the questionnaire were adequate. The results of this pilot study 75 showed that the characteristics of the questionnaire were good enough for its future use (analysis 76 of items and internal consistency, indexes of discrimination and factorial analysis) (van-der 77 Hofstadt et al., 2007-2008; Navarro-Cremades et al., 2013). The whole questionnaire collects data about various aspects of female sexual behaviour

79 (Table S1), but in this study we only used those data that the research team considered could be 80 more influential in so far as they provided information about the fear of having an unwanted 81 pregnancy.

82 The main outcome variable of the study was FBP. This was defined as women who 83 maintained sexual relations with a man and who wished to eliminate the FBP, assessed with the 84 question "What aspects of your sex life would you change?" and the possible answer "Eliminate 85 the fear of pregnancy". If the woman answered that she wished to eliminate the fear of 86 pregnancy, the variable was considered positive (yes), otherwise it was considered negative (no). 87 As FBP in young women has not been defined in the literature, the definition was considered by 88 the woman herself. This FBP could be due to such factors as pain during childbirth, fear of 89 parenthood, or fear of society's response to pregnancy outside marriage. Nevertheless, our 
90 sample was taken from university students (mean age close to 21 years), most of whom do not

91 want to have a baby. Thus, this fear is mainly due to the impossibility of leading the same sort of

92 life as a young woman who is not pregnant, as the young mother would then have to focus her

93 life on the maintenance and care of her child for a substantial amount of time, in addition to

94 being unable to finish her studies, either temporarily or permanently.

95 To analyse the possible factors related with this FBP, the research team selected from the 96 questionnaire (Table S1) the following items in order to determine their association with the

97 main outcome variable: stable relationship (yes; no), contraceptive method used (oral

98 contraceptive; condom; none), desire to increase the frequency of sexual relations (yes; no),

99 sexual partner does not always ejaculate (yes; no), desire to prolong the partner's time to orgasm

100 (yes; no), frequency of sexual intercourse with partner (6 $\rightarrow 5-7$ times/week; $5 \rightarrow 3-4$ times/week;

$1014 \rightarrow 1-2$ times/week; $3 \rightarrow 2-3$ times/month; $2 \rightarrow$ once/month; $1 \rightarrow$ Never) and age (in years).

102 The stable relationship parameter was included in the data analysis because women in a

103 casual relationship would experience more fear of failure of the contraceptive method. They

104 might be worried about parenthood with a man they barely know, or from lack of support if they

105 choose to terminate the pregnancy. The use of condoms is correlated with occasional partners

106 since in addition to the benefit of contraception a condom serves as a method for protection from 107 sexually transmitted diseases. Regarding the use of variables concerning the partner's orgasm, it 108 was logical to think that they could be associated with FBP. On the other hand, the frequency of 109 sexual intercourse with partners could affect the likelihood of pregnancy and therefore the rate of 110 FBP. Finally, a younger age could be associated with less sexual experience.

\section{Sample size}


112 A total of 472 women completed the questionnaire voluntarily and fulfilled all the inclusion

113 criteria [having had vaginal intercourse with a man during the previous three months (assessed

114 via the question Sexual Orientation) and usual contraceptive method of oral contraceptives or

115 condom, or no method (assessed via the item Method of contraception you use)]. The aim was to

116 estimate the proportion of women who experienced FBP. Assuming a confidence of $95 \%$ and a

117 maximum expected proportion $(\mathrm{p}=\mathrm{q}=0.5)$, the expected error in the estimation was $4.5 \%$.

\section{Statistical analysis}

119 As the study was undertaken in different academic years, we first checked the homogeneity of

120 the courses using the Pearson Chi square or Fisher test (qualitative data), and ANOVA or

121 Kruskal-Wallis (quantitative data). In the event of a difference over time being found the results

122 would be stratified by academic course.

123 The descriptive analysis was done using absolute and relative frequencies for the

124 qualitative variables and means plus standard deviations for the quantitative variables. A

125 multivariate logistic regression model was used to estimate the adjusted odds ratios (ORs) in

126 order to analyse the association between FBP and the other variables. This model was stratified

127 by being in a stable relationship to minimize the confounding effect of this variable. The ORs

128 were adjusted for contraceptive method used, desire to increase the frequency of sexual relations,

129 frequency of sexual intercourse with partner, partner's ejaculation (satisfactory ability and time)

130 and age (quantitatively). Finally, the multivariate model was used to calculate the prognostic

131 probabilities of FBP, transformed into charts to simplify the interpretation of the results. The

132 likelihood ratio test was carried out for the goodness-of-fit of the model. All the analyses were

133 done with a Type I error of 5\% and the confidence intervals (CI) were calculated for the more

134 relevant study parameters. The analyses were calculated using IBM SPSS Statistics 19.0. 
136 The Ethics Committee of Miguel Hernández University, Elche, (Project Evaluation Organism)

137 evaluated and authorized the study (reference DMC.FNC.01.14), ensuring the voluntary,

138 anonymous free and agreed participation, with no reward or punishment concerning their

139 university studies. In addition, the confidentiality of all the data obtained from the questionnaires

140 was guaranteed. Finally, the participants were informed verbally about the study and about the

141 information required.

142

\section{RESULTS}

144 A total of 601 female students attended lectures on the days the research team decided to give 145 out the questionnaire. Of these, nine students declined the invitation to participate and left the 146 lecture hall whilst the remainder completed the questionnaire. A total of 15 women had had no

147 sexual activity during the previous three months and were therefore excluded, 7 students failed to

148 hand in the questionnaire and 5 left it completely blank; thus a total of 565 questionnaires were

149 completed. Of these, and for this particular study, we also excluded another 93 women who used

150 a different contraceptive method to that analysed in this study. This gave a final sample of 472

151 participants who commonly used as contraception either the condom or oral contraceptives, or

152 who used no method of contraception.

153 No differences in any of the study variables (or any other variable) were found between

154 the academic years, as all the p-values were above the threshold established (5\%).

155 In the final sample 171 women experienced FBP, equivalent to $36.2 \%$ of the total sample

156 (95\% CI: 31.9-40.6\%). Table 1 shows the descriptive characteristics of the study sample, the

157 mean age of which was almost 21 years (20.7). The contraceptive method most commonly used 
158 was the condom (70.6\%), followed by oral contraceptives (19.3\%). About half the women

159 desired to have a partner with a greater ability to delay orgasm (44.1\%) and most of the partners

160 ejaculated in all their relations (95.8\%). In addition, $18.9 \%$ of the women desired to increase the

161 frequency of their sexual relations and 293 women (62.1\%) were in a stable relationship.

162 Comparison of the main characteristics taking into account whether the woman was in a stable

163 relationship showed significant differences $(p<0.05)$ in the following variables: contraceptive

164 method $(\mathrm{p}<0.001)$, desire to increase the frequency of sexual intercourse $(\mathrm{p}=0.029)$ and

165 frequency of sexual intercourse with the partner $(\mathrm{p}<0.001)$. However, the rates of FBP were

166 similar between the groups $(\mathrm{p}=0.671)$ and these rates had the following values when we

167 differentiated between relationship and contraceptive method: 1) women in a stable relationship

168 (oral, 15.6\%; condom, 45.0\%; none, 12.5\%); 2) women not in a stable relationship (oral, $21.4 \%$;

169 condom, 36.8\%; none, 46.9\%).

170 In women in a stable relationship (Table 2), the factors significantly associated with the

171 main outcome variable were type of contraceptive method used (condom) and higher frequency

172 of sexual intercourse with the partner. On the other hand, for women not in a stable relationship,

173 the only significant factor was the desire to increase the partner's ability to delay orgasm,

174 although the contraceptive method (condom or none) had significant values of ORs with a p-

175 value close to $5 \%(\mathrm{p}=0.101)$.

176 Figure 1 shows the prognostic probabilities of FBP obtained from the multivariate model.

177 Of note in the women in a stable relationship (Fig. 1A) was the great difference between those

178 who commonly used oral contraceptives or no method of contraception versus those who used a

179 condom. Fig. 1B shows the increase in the probability of FBP in relation to the less effective

180 contraceptive methods. 


\section{DISCUSSION}

\section{Summary}

184 Our results showed an important proportion of women experiencing FBP, as almost one in three 185 answered the item assessing this aspect affirmatively. Among the factors analysed, use of a 186 condom and higher frequency of sexual intercourse with the partner (only women in a stable 187 relationship), and desire to increase the partner's ability to delay orgasm (only for women not in 188 a stable relationship) were associated with this fear. Finally, the contraceptive method as an 189 associated factor for FBP in women not in a stable relationship was very relevant and close to 190 statistical significance.

191 Strengths and limitations of the study

192 The main strength of this study resides in the lack of other studies analysing the magnitude of 193 this problem and its association with female sexual behaviour. Thus, our results are innovative 194 and indicate the magnitude of FBP among women who use the two most common contraceptive 195 methods or who do not use any contraceptive method. In addition, we also analysed factors 196 associated with sexual practices indicating which groups are more likely to experience FBP. The study limitations are determined by its design. As it was a cross-sectional study we

198 199

200

201

202 203 are unable to determine any temporality between the factors studied and our main variable. This would require future longitudinal studies with predictive models to determine which women are more likely to develop FBP and then intervene early with educational activities to prevent the problem (beliefs about the efficacy of contraceptives and not using any contraceptive method).

We may have committed information bias, as there could be some women who in fact did wish to become pregnant or they may have already had a miscarriage, abortion or live birth, 
204 which would justify the fear. However, these would be in the minority, as women in Spain have

205 their first child at the age of 31.6 years and the mean age of our sample was 20.7 years (Instituto

206 Nacional de Estadística, 2012). On the other hand, the source of all the information was a

207 questionnaire with good psychometric properties (van-der Hofstadt et al., 2007-2008; Navarro-

208 Cremades et al., 2013) that gave reliability to the responses. In addition, we have defined the

209 concept of FBP for young women using their own opinion about the concept; therefore further

210 studies are needed to assess all the aspects of this fear (pain during childbirth, parenthood,

211 society's response to pregnancy outside marriage or impossibility of following the same sort of

212 life as a young woman who is not pregnant).

213 Finally, to minimize selection bias, the participants selected had all studied sexology in

214 their respective university courses. The students were therefore aware of both the use and the

215 efficacy of the contraceptive methods for preventing an undesired pregnancy or a sexually

216 transmitted disease.

217 Comparison with the existing literature

218 We have only found one study analysing, as a secondary aim, FBP in women who used just

219 hormonal contraceptives (the main aim of the study was to assess noncompliance in their use).

220 This study was a subanalysis evaluating relief on starting the menstrual cycle after having had

221 vaginal sexual intercourse involving male ejaculation, whereas in our study FBP was assessed

222 differently, analysing women who used oral contraceptives, a condom, or no method at all. Thus,

223 we can only compare our results for the women who used oral contraceptives. The magnitude

224 found in the other study was $43.9 \%$, much higher than in our study (15.6\% and $21.4 \%$,

225 depending on whether the woman was or was not in a stable relationship). The difference could

226 be related to the fact that our sample comprised persons studying healthcare sciences, and they 
227 were thus educated in both gynaecology and sexually transmitted diseases, whereas the sample in

228 the other study was taken from the general population (Lete et al., 2008).

229 Concerning the factors associated with FBP, we found that the women were more afraid

230 when they used a condom than when they used oral contraceptives. This could be a result of their

231 awareness about the lack of effectiveness of the condom when not used adequately (World

232 Health Organization, 2011). Furthermore, when women were not in a stable relationship, they 233 experienced more FBP when they did not use any contraceptive method. Accordingly, it would

234 be advisable to perform qualitative studies to attempt to determine the reasons for the causes of

235 this fear (religious, economical, etc.). On the other hand, for women not in a stable relationship

236 there was a direct relation between male ejaculation and FBP. This could be because, for greater

237 safety, the partners withdrew the penis at the time of ejaculation and on some occasions early

238 ejaculation would not permit this to be done, producing fear in the woman. Finally, a higher

239 frequency of sexual intercourse was logically associated with FBP in women in a stable

240 relationship.

241 Implications of the research

242 This study provides relevant information about understanding contraception among women who

243 will shortly become healthcare professionals. The results show that many of the women

244 experienced FBP depending on whether they used an effective contraceptive method.

245 Furthermore, one in ten students used no contraceptive method at all. We also found an

246 association between early ejaculation/higher frequency of sexual intercourse and FBP. These

247 results could be expected if none of the women used any contraceptive method at all. However,

248 around $90 \%$ of the women did use contraception and this should not influence the fear of a

249 possible pregnancy if the method is used correctly. 
The results found suggest the need to implement sexual education programmes in the

251 faculties teaching healthcare sciences, aimed at reducing the number of unwanted pregnancies

252 and sexually transmitted diseases, both among these women and among the general population

253 who will in the future be seen by these women. The planning of these programmes would benefit

254 from qualitative studies to help understand the reasons behind this fear, as the responses given

255 would be very useful in designing these educational programmes. Moreover, as well as the

256 aforementioned qualitative studies, other studies could also be conducted to determine whether

257 the proper use of contraceptives results in less FBP; i.e., assessing incompliance taking oral

258 contraceptives and the proper use of male condoms. This could help us determine whether a

259 woman who is aware that she is using contraception correctly experiences less FBP.

260

\section{CONCLUSIONS}

262 A high proportion of women soon to become healthcare professionals experienced FBP, 263 depending on the use of efficient contraceptive methods. This may be due to a lack of

264 understanding about the correct use and efficacy of these methods, possibly because of a lack of

265 sexual education in the healthcare sciences faculties. A possible solution to this problem involves

266 educational programmes to help eliminate incorrect beliefs and attitudes about the use of

267 contraceptive methods when the male partner ejaculates, as well as information about how to use

268 each contraceptive method effectively. Qualitative studies would be useful to design these

269 educational programmes.

270

271 ACKNOWLEDGMENTS 
272 The authors thank the Department of Applied Psychology at Miguel Hernández University,

273 Elche, for allowing us to use the questionnaire for this study, and Felipe Navarro Sánchez for

274 helping with the computerised database. The authors also thank Maria Repice and Ian Johnstone

275 for help with the English language version of the text. 


\section{REFERENCES}

277 Instituto Nacional de Estadística. Indicadores demográficos básicos. 2012. Available at

278 http://www.ine.es (accessed June 2014).

279

280 Lete I, Doval JL, Pérez-Campos E, Lertxundi R, Correa M, de la Viuda E, Gómez MA, González 281 JV, Martínez MT, Mendoza N, Robledo J. 2008. Self-described impact of noncompliance among 282 users of a combined hormonal contraceptive method. Contraception 77:276-282.

283

284 Navarro-Cremades F, Hernández Serrano R, Tirado González S, Rodríguez-Marín J, Van-der 285 Hofstadt CJ, Vinci P, Llisterri-Caro JL, Llinas-Santacreu G. 2013. Propiedades psicométricas del 286 Cuestionario sobre Sexualidad Femenina CPA. In: García Rojas AD, Cabello Santamaría F, eds. 287 Actualizaciones en sexología clínica y educativa. Huelva, Spain: Universidad de Huelva 288 Publicaciones, 327-328.

289

290 Rosenberg M, Waugh M, Meehan T. 1995. Use and misuse of oral contraceptives: risk indicators 291 for poor pill taking and discontinuation. Contraception 51:283-288.

292

293 Trusell J, Kost K. 1987. Contraceptive failure in the United States: a critical review of the 294 literature. Studies in Family Planning 18:237-283.

295

296 van-der Hofstadt CJ, Antón-Ruiz FA, Tirado S, Navarro-Cremades F. 2007-2008. Hábitos 297 sexuales en mujeres estudiantes de medicina. Cuadernos de Medicina Psicosomática 84-85:3229848. 
299

300 World Health Organization. 2005. Selective practice recommendations for contraceptive use. 301 Geneva: World Health Organization.

302

303 World Health Organization. 2010. Medical elegibility criteria for contraceptive use. Geneva:

304 World Health Organization.

305

306 World Health Organization. 2011. Family Planning. Fact sheet No. 351.

307 Geneva: World Health Organization.

308 
1

Probability of fear of becoming pregnant among female university healthcare students in a Spanish region. 2005-2009 data. 


\section{A. Being in a stable relationship.}

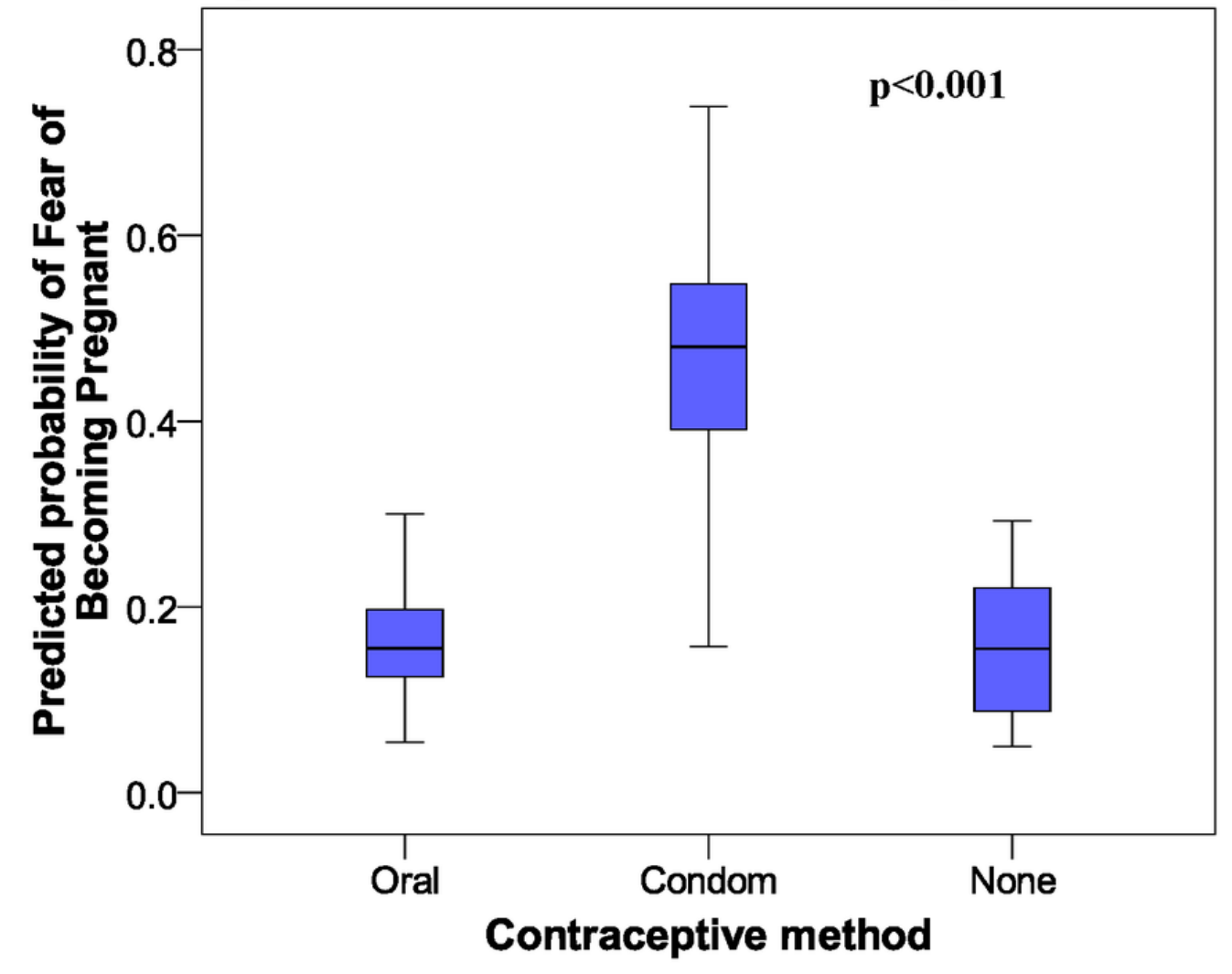

\section{B. Not being in a stable relationship.}

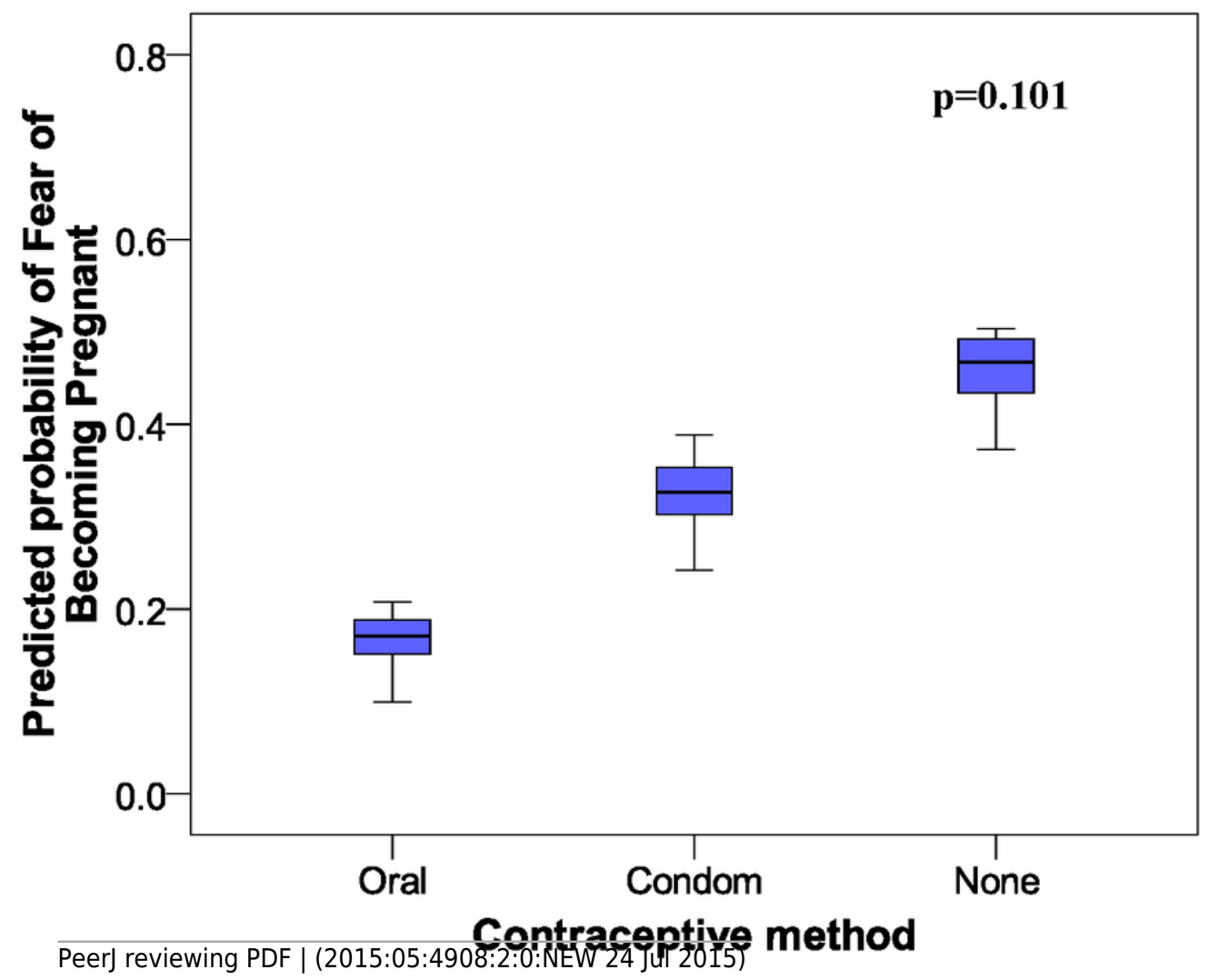


Table $\mathbf{1}_{\text {(on next page) }}$

Analysis of being in a stable relationship among female university healthcare students in a Spanish region. 2005-2009 data.

Abbreviations: $\mathrm{n}(\%)$, absolute frequency (relative frequency); $\mathrm{x} \pm \mathrm{s}$, mean \pm standard deviation; FBP, fear of becoming pregnant. Frequency of sexual intercourse with partner (6] 5-7 times/week; $5 \square$ 3-4 times/week; $4 \square \quad$ 1-2 times/week; $3 \square$ 2-3 times/month; $2 \square$ once/month; 11 Never). 


\begin{tabular}{|c|c|c|c|c|}
\hline Variable & $\begin{array}{c}\text { Total } \\
\mathrm{n}=472 \\
\mathrm{n}(\%) / \mathrm{x} \pm \mathrm{S}\end{array}$ & $\begin{array}{c}\text { In a stable } \\
\text { relationship } \\
\mathrm{n}=293(62.1 \%) \\
\mathrm{n}(\%) / \mathrm{x} \pm \mathrm{s}\end{array}$ & $\begin{array}{c}\text { Not in a stable } \\
\text { relationship } \\
\mathrm{n}=179(37.9 \%) \\
\mathrm{n}(\%) / \mathrm{x} \pm \mathrm{s}\end{array}$ & p-value \\
\hline FBP & 171(36.2) & $104(35.5)$ & $67(37.4)$ & 0.671 \\
\hline Contraceptive method: & & & & \\
\hline & & & & $<0.001$ \\
\hline Condom & $333(70.6)$ & $200(68.3)$ & $133(74.3)$ & \\
\hline None & $48(10.2)$ & $16(5.5)$ & $32(17.9)$ & \\
\hline $\begin{array}{l}\text { Desire to increase } \\
\text { partner's ability to delay } \\
\text { orgasm }\end{array}$ & $208(44.1)$ & $55(18.9)$ & $34(19.0)$ & 0.980 \\
\hline $\begin{array}{l}\text { Partner can not always } \\
\text { ejaculate }\end{array}$ & $20(4.2)$ & $11(3.8)$ & $9(5.0)$ & 0.505 \\
\hline $\begin{array}{l}\text { Desire to increase the } \\
\text { frequency of sexual } \\
\text { intercourse }\end{array}$ & $89(18.9)$ & $118(40.3)$ & $90(50.6)$ & 0.029 \\
\hline Age (years) & $20.7 \pm 2.4$ & $20.7 \pm 2.6$ & $20.7 \pm 2.1$ & 0.922 \\
\hline $\begin{array}{l}\text { Frequency of sexual } \\
\text { intercourse with the } \\
\text { partner }\end{array}$ & $3.3 \pm 1.2$ & $3.1 \pm 1.0$ & $3.8 \pm 1.3$ & $<0.001$ \\
\hline
\end{tabular}


Table 2 (on next page)

Analysis of fear of becoming pregnant among female university healthcare students in a Spanish region. 2005-2009 data.

Abbreviations: FBP, fear of becoming pregnant; Adj. OR, adjusted odds ratio; $\mathrm{Cl}$, confidence interval. Frequency of sexual intercourse with partner (6 $\square$ 5-7 times/week; $5 \square$ 3-4

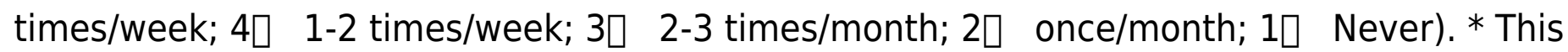
variable was not included in the model due to convergence problems. Goodness-of-fit of the models: 1) In a stable relationship: $\mathrm{X} 2=36.8, \mathrm{p}<0.001 ; 2)$ Not in a stable relationship: $\mathrm{X} 2=15.5, \mathrm{p}=0.017$. 


\begin{tabular}{|c|c|c|c|c|}
\hline Variable & $\begin{array}{l}\text { Adj. OR for } \\
\text { women in a } \\
\text { stable } \\
\text { relationship } \\
(95 \% \mathrm{CI})\end{array}$ & $\begin{array}{c}\mathrm{p}- \\
\text { value }\end{array}$ & $\begin{array}{c}\text { Adj. OR for } \\
\text { women not in a } \\
\text { stable } \\
\text { relationship } \\
(95 \% \mathrm{CI})\end{array}$ & $\begin{array}{c}\mathrm{p}- \\
\text { value }\end{array}$ \\
\hline $\begin{array}{l}\text { Contraceptive method: } \\
\text { Oral contraceptive } \\
\text { Condom } \\
\text { None }\end{array}$ & $\begin{array}{c}1 \\
3.49(1.74,7.02) \\
0.68(0.13,3.59)\end{array}$ & $<0.001$ & $\begin{array}{c}1 \\
2.13(0.53,8.54) \\
4.56(0.99,21.06)\end{array}$ & 0.101 \\
\hline $\begin{array}{l}\text { Desire to increase } \\
\text { partner's ability to delay } \\
\text { orgasm }\end{array}$ & $1.33(0.70,2.53)$ & 0.393 & $3.59(1.60,8.04)$ & 0.002 \\
\hline $\begin{array}{l}\text { Partner can not always } \\
\text { ejaculate }\end{array}$ & $0.78(0.18,3.26)$ & 0.728 & $*$ & $*$ \\
\hline $\begin{array}{l}\text { Desire to increase the } \\
\text { frequency of sexual } \\
\text { intercourse }\end{array}$ & $1.46(0.86,2.48)$ & 0.163 & $1.11(0.56,2.21)$ & 0.770 \\
\hline Age (years) & $0.92(0.81,1.04)$ & 0.180 & $0.87(0.71,1.05)$ & \begin{tabular}{|l|}
0.147 \\
\end{tabular} \\
\hline $\begin{array}{l}\text { Frequency of sexual } \\
\text { intercourse with the } \\
\text { partner }\end{array}$ & $1.31(0.81,1.04)$ & 0.047 & $0.98(0.75,1.27)$ & 0.866 \\
\hline
\end{tabular}

